\title{
Cardiac Involvement in Children With COVID-19
}

\author{
UTKARSH KOHLI ${ }^{1}$ AND RAKESH LODHA ${ }^{2}$ \\ From ${ }^{1}$ Section of Pediatric Cardiology, Division of Pediatrics, Comer Children's Hospital and Pritzker School of Medicine of the \\ University of Chicago, Chicago, IL, USA; and ${ }^{2}$ Department of Pediatrics, All India Institute of Medical Sciences, New Delhi, India. \\ Correspondence to: Dr Utkarsh Kohli, Assistant Professor of Pediatrics, Section of Pediatric Cardiology, Division of Pediatrics, \\ University of Chicago, 5481 S Maryland Ave., RM-C104E, MC 4051, Chicago, IL 60637, USA. utkarshkohli@gmail.com
}

In contrast to adults, severe acute respiratory syndrome coronavirus 2 (SARS-CoV-2) usually leads to a mild illness in children. However, a few children have been reported to have severe manifestations including pneumonia, acute kidney injury, multi-organ failure and cardiac injury. This review focuses on cardiac involvement during SARS-CoV-2 infection and the recently described likely immune mediated postCOVID-19 syndrome. Therapeutic strategies for cardiac dysfunction in both these settings are briefly discussed.

Keywords: SARS-CoV-2, MIS-C, Myocarditis, Coronary dilation, Hypotension, Shock.

Published online: August 07, 2020; PII: S097475591600222

$\mathrm{W}$ e are currently in the midst of a SARSCoV-2 mediated novel coronavirus disease 2019 (COVID-19) pandemic. In contrast to adults, SARS-CoV-2 mostly leads to a mild illness in children typically manifested as fever, cough or gastrointestinal symptoms [1,2]. However, a few children have been reported to manifest severe disease which has been characterized by pneumonia, acute kidney injury, liver injury, metabolic acidosis, neurological injury, rhabdomyolysis, multi-organ system failure, and cardiac injury [1,3-5]. This review focuses on cardiac involvement during COVID-19 infection and the multisystem inflammatory syndrome in children (MIS-C) $[6,7]$. Therapeutic strategies for cardiac dysfunction in both these settings are briefly discussed.

\section{CARDIAC INVOLVEMENT IN SARS-COV-2 INFECTION}

Cardiac involvement, which can manifest as acute myocardial injury with elevated plasma troponin concentration, acute coronary events, heart failure and arrhythmias is both common and associated with a higher morbidity and mortality in adults with COVID-19 [8-10]. Hypothesized mechanisms of cardiac injury include direct viral invasion leading to cardiomyocyte death and inflammation and indirect mechanisms of injury - cardiac stress due to respiratory failure and hypoxemia and cardiac inflammation secondary to severe systemic hyper-inflammation, which is thought to be mediated by cytokines such as interleukin (IL)-6, IL-2, IL-7, TNF (tumor necrosis factor)- $\alpha$ and IFN (interferon)- $\gamma$ [11]. Cardiac involvement during COVID-19 is not common in children who require pediatric intensive care unit (PICU) admission; use of inotropes was reported in 12 (25\%) patients admitted to a North American PICU in a recent study [4]. The plasma concentration of cardiac bio-markers and echocardiographic findings in these patients were not reported, therefore it is unclear if inotropic requirement was due to primary cardiac dysfunction [4].

Cardiac involvement in patients with COVID-19 has included elevation in cardiac biomarkers such as troponin, CPK-MB, and pro-brain type natriuretic peptide (pro-BNP), echocardiographic abnormalities such as diminished left ventricular function with segmental or global wall motion abnormality and coronary artery dilation, and electrical abnormalities such as sinus tachycardia, atrial arrhythmias, non sustained ventricular tachycardia, first-degree atrioventricular block, premature atrial and ventricular contractions, and incomplete right bundle branch block [3,12-17] (Table 1). In one of the largest pediatric series $(n=2135)$ from China, $0.6 \%$ of children had symptomatic myocardial injury and heart failure $[18,19]$.

It is difficult to draw any firm conclusions, given the small numbers and lack of any systematic prospective studies. However, currently available data indicates that cardiac involvement in children with COVID-19 is not common. In addition to clinical evaluation, electrocardiography and cardiac imaging, cardiac biomarkers such as plasma troponin, CK-MB and pro-BNP may be helpful in diagnosis. IVIG may have a role in treatment of children with cardiac involvement. The role of other drugs such as remdesivir and hydroxychloroquine is unclear at this time. 
Table 1 Cardiac Involvement in Children With Coronavirus Disease 19

\begin{tabular}{|c|c|c|c|c|c|}
\hline $\begin{array}{l}\text { Author, No. of } \\
\text { patients }\end{array}$ & $\begin{array}{l}\text { Age, sex, } \\
\text { ethnicity }\end{array}$ & $\begin{array}{l}\text { Clinical } \\
\text { presentation }\end{array}$ & $\begin{array}{l}\text { Cardiac biomarkers } \\
\text { and ECG findings }\end{array}$ & Echo findings & Treatment \\
\hline $\begin{array}{l}\text { Cui, et al. [3], } \\
1\end{array}$ & $\begin{array}{l}55 \mathrm{~d}, \mathrm{~F} \\
\text { Chinese }\end{array}$ & Respiratory symptoms & Mild $\uparrow$ troponin & - & - \\
\hline $\begin{array}{l}\text { Giacomet, etal. } \\
{[12], 1}\end{array}$ & $2 \mathrm{mo}$ & $\begin{array}{l}\text { Fever and sinus } \\
\text { tachycardia }\end{array}$ & $\begin{array}{l}\uparrow \text { troponin and } \\
\uparrow \mathrm{BNP}\end{array}$ & $\begin{array}{l}\text { Hypokinesia of the } \\
\text { inferior LV wall and } \\
\text { the inferior interventri- } \\
\text { cular septum. } \\
\text { Mild } \uparrow \text { LVEF }\end{array}$ & $\operatorname{IVIG}(2 \mathrm{~g} / \mathrm{kg})$ \\
\hline $\begin{array}{l}\text { Sun, et al. [13], } \\
1\end{array}$ & $\begin{array}{l}13 \text { mo, } \mathrm{M} \\
\text { Chinese }\end{array}$ & $\begin{array}{l}\text { Multiorgan dysfunc- } \\
\text { tion including cardiac } \\
\text { dysfunction }\end{array}$ & - & - & $\begin{array}{l}\text { Antiviral drugs, } \\
\text { Glucocorticoids, } \\
\text { IVIG, and } \\
\text { Plasmapheresis }\end{array}$ \\
\hline $\begin{array}{l}\text { Xia, et al. [14], } \\
5\end{array}$ & $\begin{array}{l}1 \mathrm{~d}-14 \mathrm{y} \\
\text { Chinese }\end{array}$ & $\begin{array}{l}\text { Fever, cough, } \\
\text { GI symptoms }\end{array}$ & $\begin{array}{l}\uparrow \mathrm{CPK}-\mathrm{MB}(n=5), \\
\text { sinus tachycardia } \\
(n=1), \text { atrial tachy } \\
\text { cardia }(n=1), \text { PACs, } \\
\text { PVCs and prolonged } \\
\text { PR interval }(n=1), \\
\text { and incomplete RBBB } \\
(n=1)\end{array}$ & - & - \\
\hline $\begin{array}{l}\mathrm{Su}, \text { et al. }[15] \text {, } \\
6\end{array}$ & $\begin{array}{l}11 \mathrm{mo}- \\
9.75 \mathrm{y} \\
3 \mathrm{M} / 3 \mathrm{~F} \\
\text { Chinese }\end{array}$ & Fever, cough & 个CPK-MB & - & $\begin{array}{l}\text { Lopinavir/ } \\
\text { Ritonavir, } \\
\text { Interferon }\end{array}$ \\
\hline $\begin{array}{l}\text { Samuel, et al. } \\
{[16], 6}\end{array}$ & $12-20 y$ & & $\begin{array}{l}\uparrow \text { troponin }(n=2), \\
\text { monomorphic VT } \\
(n=5), \text { sustained atrial } \\
\text { tachycardia }(n=1)\end{array}$ & $\begin{array}{l}\text { LV dysfunction }(n=2) \text {, } \\
\text { LV dilation }(n=1) \text {, } \\
\text { large circumferential } \\
\text { pericardial effusion } \\
(n=1)\end{array}$ & $\begin{array}{l}\text { Beta-blocker }(n=2), \\
\text { Amiodarone }(n=1)\end{array}$ \\
\hline $\begin{array}{l}\text { Oberweis, et al. } \\
{[17], 1}\end{array}$ & $\begin{array}{l}8 \mathrm{y}, \mathrm{M} \\
\text { African }\end{array}$ & $\begin{array}{l}\text { Fever, cough, malaise, } \\
\text { weight loss }\end{array}$ & $\begin{array}{l}\uparrow \text { troponin, } \\
\uparrow \mathrm{BNP}\end{array}$ & $\begin{array}{l}\text { LV dysfunction, trace } \\
\text { mitral regurgitation } \\
\text { and small pericardial } \\
\text { effusion }\end{array}$ & $\operatorname{IVIG}(2 \mathrm{~g} / \mathrm{kg})$ \\
\hline
\end{tabular}

LV: Left ventricle; BNP: Brain type natriuretic peptide; IVIG: Intravenous Immune Globulin; PAC: Premature Atrial Contraction; PVC: Premature Ventricular Contraction; CPK-MB: Creatine Phosphokinase-Muscle Brain subtype; LVEF: Left Ventricular Ejection Fraction.

\section{CARDIAC INVOLVEMENT IN MIS-C}

A few weeks following the peak of COVID-19 epidemic in the US and the European Union, a novel systemic illness which clinically overlaps with Kawasaki disease with or without shock syndrome, macrophage activation syndrome (MAS) and toxic shock syndrome (TSS) was reported in children. This entity was labeled as Multisystem inflammatory syndrome in children (MISC) by the Centers for Disease Control and Prevention (CDC), USA and by the World Health Organization (WHO) [6,7]. A few cases have also been reported from India [20].

Cardiac involvement as evidenced by perturbation of cardiac chamber size and/or function, coronary artery abnormalities (ectasia, aneurysm) or elevated cardiac biomarkers such as troponin or pro-BNP is not only common in children with MIS-C but can also be severe (Web Table I). A vast majority of children with MIS-C had been previously healthy; a few have had minor comorbidities such as asthma and obesity. In addition to fever and weakness/malaise, gastrointestinal symptoms have been common at presentation. Many of these children have had marked hemodynamic instability requiring inotropic support and intensive care at admission. In addition, a small proportion has required extracorporeal membrane oxygenation support; though, mortality has been low [20-27]. In contrast to patients 
with typical Kawasaki disease, atypical features including a higher incidence of cardiac involvement (60\%), shock syndrome like features (50\%), MAS (50\%) and need for steroids following IVIG administration $(80 \%)$ were noted in a previous study [22].

The precise mechanisms that underlie genesis of MIS-C and its cardiac manifestations are yet unknown. However, given the fact that a vast majority of children have presented 4-6 weeks after the peak of the local COVID-19 epidemic, many have been SARS-CoV-2 PCR negative but antibody positive, have had markedly elevated inflammatory markers such as C-reactive protein, erythrocyte sedimentation rate, fibrinogen, procalcitonin, ferritin, or interleukin 6, and have responded well to IVIG and immunomodulators; an immune origin is likely. Genetic factors may underlie the overall rarity of MIS-C and relative preponderance in African Americans.

Given the multiorgan dysfunction and potential for sudden and severe decompensation in patients with MIS$\mathrm{C}$, our practice has been to admit these patients to PICU where they are cared for by a team which involves specialists from pediatric rheumatology/immunology, pediatric critical care, pediatric cardiology, pediatric infectious diseases, and pediatric hematology. Inotropes should be initiated in children with MIS-C if clinically indicated and ECMO should be reserved for children with inotrope-refractory shock. In addition to clinical markers, mixed venous oxygen saturation and plasma lactate can be used to guide therapy. A vast majority of children with MIS-C have responded well to IVIG (1-2 g/ $\mathrm{kg}$ ), which as per the recently proposed American College of Rheumatology guidelines [28] should be the initial therapeutic agent. Though the data are scarce, patients with suboptimal clinical response (hemodynamic instability) or biochemical response (persistent elevation in inflammatory markers) to IVIG have benefitted from steroids (intravenous methylprednisolone $2 \mathrm{mg} / \mathrm{kg} /$ day) or immunomodulators such as anakinra (interleukin-1 antagonist) (2-8 mg/kg/day subcutaneous injection once or twice a day, maximum dose: $100 \mathrm{mg}$ twice a day) and tocilizumab (interleukin-6 antagonist). The dosing of tocilizumab for systemic onset juvenile idiopathic arthritis is $12 \mathrm{mg} / \mathrm{kg}$ intravenous or $162 \mathrm{mg}$ subcutaneous every other week for those weighing less than $30 \mathrm{~kg}$ and 8 $\mathrm{mg} / \mathrm{kg}$ intravenous every other week or $162 \mathrm{mg}$ subcutaneous every week for those weighing $>30 \mathrm{~kg}$. The optimal dose and dosing frequency for MIS-C is not known; intravenous doses of 400-800 $\mathrm{mg}$ and a subcutaneous dose of $162 \mathrm{mg}$ has been used in adults with COVID-19 associated cytokine release syndrome [29], and $8 \mathrm{mg} / \mathrm{kg}$ in children [30]. Though adjunctive immune modifying therapies such as anakinra, tocilizumab and convalescent plasma have been used in patients with both acute COVID-19 and MIS-C, their role has not been systematically evaluated. Given the potential risk of thrombotic complications, we also initiate aspirin and low molecular weight heparin at admission, both of which we discontinue upon normalization of inflammatory markers. In addition to aspirin and low molecular weight heparin, we have typically discharged these patients on oral steroids which are gradually tapered as guided by their clinical status and cardiac and inflammatory biomarkers. Cardiac imaging with a focus on coronary arteries is obtained at regular intervals after discharge [28].

Cardiac involvement in children with COVID-19 is uncommon; however, a handful of patients have had severe involvement with markedly diminished ventricular function and hemodynamic instability. These patients have benefited from IVIG. The role of antivirals such as remdesivir, hydroxychloroquine, and adjunctive immunomodulatory therapies in patients with COVID-19 and cardiac involvement is unclear at this time. Cardiac involvement as evidenced by perturbation of cardiac chamber size and/or function, coronary artery abnormalities (ectasia, aneurysm) or elevated cardiac biomarkers such as troponin or pro-BNP is not only common in children with MIS-C but can also be severe. These children have responded to IVIG and or corticosteroids. A few have required additional immunomodulators such as anakinra and tocilizumab.

\section{REFERENCES}

1. Castagnoli R, Votto M, Licari A, Brambilla I, Bruno R, Perlini $\mathrm{S}$, et al. Severe acute respiratory syndrome coronavirus 2 (SARS-CoV-2) infection in children and adolescents: A Systematic Review [published online ahead of print, 2020 Apr 22]. JAMA Pediatr. 2020;10.1001/ jamapediatrics.2020.1467.

2. Ludvigsson JF. Systematic review of COVID-19 in children shows milder cases and a better prognosis than adults. Acta Paediatr. 2020;109:1088-95.

3. Cui Y, Tian M, Huang D, Wang X, Huang Y, Fan Li, et al. A 55-day-old female infant infected with 2019 novel coronavirus disease: Presenting with pneumonia, liver injury, and heart damage. J Infect Dis. 2020;221:1775-81.

4. Shekerdemian LS, Mahmood NR, Wolfe KK, Riggs BJ, Ross CE, McKiernan CA, et al. Characteristics and outcomes of children with coronavirus disease 2019 (COVID-19) infection admitted to US and Canadian pediatric intensive care units [published online ahead of print, 2020 May 11]. JAMA Pediatr. 2020;10.1001/ jamapediatrics.2020.1948.

5. Gefen AM, Palumbo N, Nathan SK, Singer PS, Castellanos-Reyes LJ, Sethna CB. Pediatric COVID-19associated rhabdomyolysis: A case report. Pediatr Nephrol. 
2020;35:1517-20.

6. Centers for Disease Control and Prevention. Multisystem Inflammatory Syndrome in Children (MIS-C) Associated with Coronavirus Disease 2019 (COVID-19). Available from: https://emergency.cdc.gov/han/2020/han00432.asp. Accessed May 29, 2020

7. World Health Organization. Multisystem inflammatory syndrome in children and adolescents temporally related to COVID-19 Available from: https://www.who.int/newsroom/commentaries/detail/multisystem-inflammatorysyndrome-in-children-and-adolescents-with-covid-19. Accessed May 29, 2020

8. Bansal M. Cardiovascular disease and COVID-19. Diabetes Metab Syndr. 2020;14:247-50.

9. Inciardi RM, Lupi L, Zaccone G, Italia L, Raffo M, Tomasoni D, et al. Cardiac involvement in a patient with coronavirus disease 2019 (COVID-19). JAMA Cardiol. 2020;5:1-6.

10. Shi S, Qin M, Shen B, Cai Y, Liu T, Yang F, et al. Association of cardiac injury with mortality in hospitalized patients with COVID-19 in Wuhan, China. JAMA Cardiol. 2020;5:802-10.

11. Akhmerov A, Marbán E. COVID-19 and the heart. Circ Res. 2020;126:1443 55.

12. Giacomet V, Manfredini VA, Meraviglia G, Peri CF, Sala A, Longoni E, et al. Acute inflammation and elevated cardiac markers in a two-month-old infant with severe acute respiratory syndrome coronavirus 2 infection presenting with cardiac symptoms. Pediatr Infect Dis J. 2020;39:e149-51.

13. Sun D, Li H, Lu XX, Xiao H, Ren J, Zhang F, et al. Clinical features of severe pediatric patients with coronavirus disease 2019 in Wuhan: A single centers observational study. World J Pediatr. 2020;16:251-9.

14. Xia W, Shao J, Guo Y, Peng X, Li Z, Hu D. Clinical and CT features in pediatric patients with COVID-19 infection: Different points from adults. Pediatr Pulmonol. 2020; 55:116974.

15. Su L, Ma X, Yu H, Zhang Z, Bian P, Han Y, et al. The different clinical characteristics of corona virus disease cases between children and their families in China - the character of children with COVID-19. Emerg Microbes Infect. 2020;9:707-13.

16. Samuel S, Friedman RA, Sharma C, Ganigara M, Mitchell $\mathrm{E}$, Schleien $\mathrm{C}$, et al. Incidence of arrhythmias and electrocardiographic abnormalities in symptomatic pediatric patients with PCR positive SARS-CoV-2 infection including drug induced changes in the corrected QT interval (QTc). Heart Rhythm. 2020;S1547-5271: 30632-9.

17. Oberweis ML, Codreanu A, Boehm W, Olivier D, Pierron $\mathrm{C}$, Tsobo $\mathrm{C}$, et al. Pediatric Life-threatening coronavirus disease 2019 with myocarditis. Pediatr Infect Dis J. 2020;39:e147-e149.

18. Dong Y, Mo X, Hu Y, Qi X, Jiang F, Jiang Z, et al. Epidemiology of COVID-19 among children in China. Pediatrics. 2020; e20200702.

19. Sanna G, Serrau G, Bassareo PP, Neroni P, Fanos V,
Marcialis MA. Children's heart and COVID-19: Up-todate evidence in the form of a systematic review. Eur J Pediatr. 2020;179:1079-87.

20. Dhanalakshmi K, Venkataraman A, Balasubramanian S, Madhusudan M, Amperayani S, Putilibai S, et al. Epidemiological and clinical profile of pediatric inflammatory multisystem syndrome - temporally associated with SARS-CoV-2 (PIMS-TS) in Indian children [published online ahead of print, 2020 Aug 6]. Indian Pediatr. 2020; S097475591600220.

21. Belhadjer Z, Méot M, Bajolle F, Khraiche D, Legendre A, Abakka $\mathrm{S}$, et al. Acute heart failure in multisystem inflammatory syndrome in children (MIS-C) in the context of global SARS-CoV-2 pandemic [published online ahead of print, 2020 May 17]. Circulation. 2020;10.1161/ CIRCULATIONAHA.120.048360.

22. Verdoni L, Mazza A, Gervasoni A, Martelli L, Ruggeri M, Ciuffreda M, et al. An outbreak of severe Kawasaki-like disease at the Italian epicentre of the SARS-CoV-2 epidemic: An observational cohort study. Lancet. 2020;395:1771-78.

23. Riphagen S, Gomez X, Gonzalez-Martinez C, Wilkinson $\mathrm{N}$, Theocharis P. Hyper inflammatory shock in children during COVID-19 pandemic. Lancet. 2020;395:1607-8.

24. Chiotos K, Bassiri H, Behrens EM, Blatz AM, Chang J, Diorio $\mathrm{C}$, et al. Multisystem inflammatory syndrome in children during the COVID-19 pandemic: A case series. J Pediatric Infect Dis Soc. 2020;9:393-8.

25. Feldstein LR, Rose EB, Horwitz SM, Collins JP, Newhams $\mathrm{MM}$, Son MBF, et al. Multisystem inflammatory syndrome in U.S. children and adolescents. $N$ Engl J Med. 2020;383:334-46.

26. Dufort EM, Koumans EH, Chow EJ, Rosenthal EM, Muse A, Rawlands J, et al. Multisystem inflammatory syndrome in children in New York State. $\mathrm{N}$ Engl $\mathrm{J}$ Med. 2020;383:347-58.

27. Whittaker E, Bamford A, Kenny J, Kaforou M, Jones CE, Shah P, et al. Clinical Characteristics of 58 Children With a Pediatric Inflammatory Multisystem Syndrome Temporally Associated With SARS-CoV-2 [published online ahead of print, 2020 Jun 8]. JAMA. 2020;e2010369.

28. American College of Rheumatology. Clinical Guidance for Pediatric Patients with Multisystem Inflammatory Syndrome in Children (MIS-C) Associated with SARSCoV-2 and Hyperinflammation in COVID-19. Available from: https://www.rheumatology.org/ Portals/0/Files/ ACR-COVID-19-Clinical-Guidance-Summary-MIS-CHyperinflammation .pdf. Accessed August 7, 2020.

29. Hassoun A, Thottacherry ED, Muklewicz J, Aziz QU, Edwards J. Utilizing tocilizumab for the treatment of cytokine release syndrome in COVID-19. J Clin Virol. 2020;128:104443.

30. Balasubramanian S, Nagendran TM, Ramachandran B, Ramanan AV. Hyper-inflammatory syndrome in a child with COVID-19 treated successfully with intravenous immunoglobulin and tocilizumab. Indian Pediatr. 2020;57:681-3. 


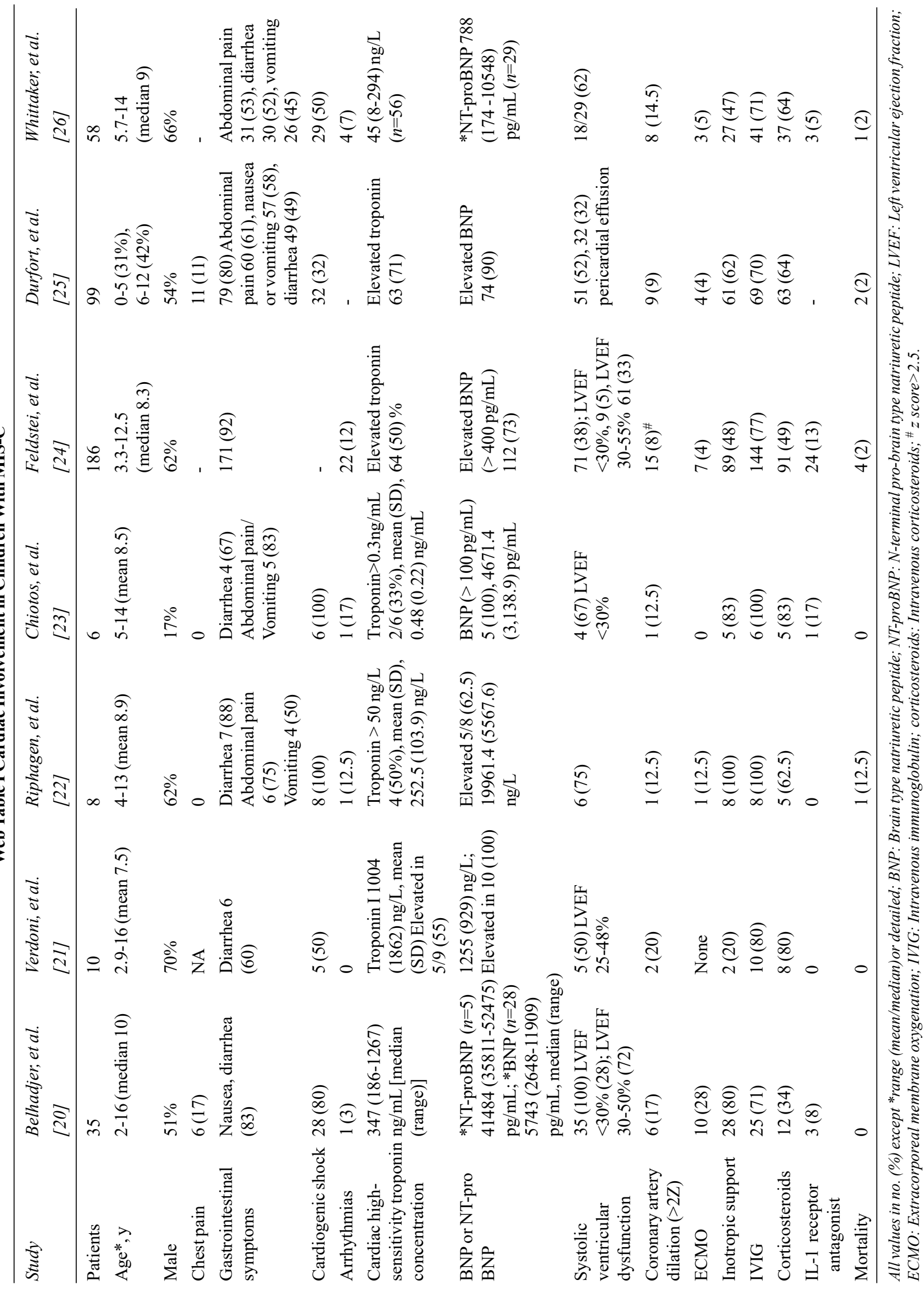

